\title{
Fingerprint based Gender Identification using Discrete Wavelet Transform and Gabor Filters
}

\author{
Shivanand Gornale \\ Department of \\ Computer Science, \\ Rani Channamma \\ University, Belagavi, \\ Karnataka
}

\author{
Abhijit Patil \\ Research Scholar \\ Department of \\ Computer Science, \\ Rani Channamma \\ University, \\ Belagavi, Karnataka
}

\author{
Veersheety C. \\ Research Scholar \\ Department of \\ Computer Science, \\ Karnatak Arts Science and \\ Commerce College, \\ Bidar, Karnataka
}

\begin{abstract}
Usage of biometrics in day today life is becoming inevitable. Fingerprints are one of the most notable biometric technologies and are considered legitimate evidence all over the world. Research carried out so for on gender identification techniques is from the face image with relatively more complex resulting in high accuracy. Fingerprint trait can also be used for estimation of gender information and classification. In the proposed work DWT and Gabor based features are used to extract the gender information from fingerprints for classification of male and female. For experimentation fingerprint images of 74 persons with different age and gender is collected and stored in database. Accordingly in the experimental observations an $85 \%$ and $87 \%$ classification rate is achieved and by using Gabor filters the top-class accuracy of $97 \%$ is obtained.
\end{abstract}

\section{Keywords}

Gender identification, fingerprint, DWT, QDA, LDA, Gabor filters.

\section{INTRODUCTION}

Since the first moment of life we try to recognize mother and father and during all existence we constantly perform gender recognition, often without being aware of it.

The term "biometrics" is derived from the Greek words bio (life) and metric (to measure). Primarily dermal ridges (ridge counts) are formed during the gestational weeks 12-19 and the resulting fingerprint ridge configuration (fingerprint) is fixed permanently [2]. Fingerprints are unvarying but its size and shape may change and differs with age, but basic patterns of the fingerprint remains unchanged [3].

Joao De Barros, a [1] European explorer is credited with recording the first known system of fingerprinting in the 14th century, Since then biometric systems have been successfully deployed in a number of real-world applications, but biometrics is not yet a fully solved problem. We aim to examine the impact of gender identification on the enhancement of the performance of the biometric system by using biometric traits i.e. fingerprint. The related work is reviewed and reported in Section 2. The methodology to employ and the flow of proposed work are described in Section 3. Experimental result is briefed in section 4 and comparison of result is shown in section 5 Concluding remarks are reported in Section 6.

\section{RELATED WORK}

Gnanasivam P et al[6] Proposed methodology has focused on male and female identification using fingerprint through frequency domain analysis to estimate male and female by analyzing fingerprints. FFT, DCT and PSD are used to extract features on a database of 400 persons of different age and gender. A threshold value is used to classify the gender. The accuracy of $92.88 \%$ for male and $94.85 \%$ for female was obtained.

RituKaur [7] et al proposed methodology of gender identification using fingerprint DWT and SVD is used extract the feature set. This algorithm is experimented with the internal database of 3570 fingerprints. They obtained Fingerwise gender classification which is $94.32 \%$ for the left hand little fingers of female persons and $95.46 \%$ for the left hand index finger of male. Gender classification for any finger of male is obtained as $91.67 \%$ and $84.69 \%$ for female.

RituKaur et al [8] proposed method that extracts feature set from FFT, DCT and PSD .A dataset of 220 persons of different age and gender is collected as internal database. An optimal threshold value is used to classify the gender. They have obtained $90 \% 79.07 \%$ respectively.

Naveen Kumar Jain et al [9] proposed methodology 2D-DWT is used to find the frequency domain vector and SVD are used to extract feature of the non-zero singular values. The K-NN classifier is used to classify the gender by fingerprint. The proposed method is experimented on database of 100 fingerprints of left hand index finger, 50 males and 50 females belonging to the same age group and achieved the success rate of more than $80 \%$.

$\mathrm{R}$ Jackson et al[10] proposed a method in which features are computed through 2D DWT and PCA on the dataset of 400 fingerprints of aged 12-60 and the overall success rate of classification in age estimation was around $68 \%$.

S. S. Gornale and Kruthi R et al [11] proposed method for gender identification which is carried out using frequency and spatial domain by combined features using FFT, Eccentricity and Major Axis Length on database of 450 male and 550 female samples of left thumb impression of each sample were considered. An optimal threshold is chosen to achieve results. The classification rate of $80 \%$ for male \& $78 \%$ for female was obtained.

Pallavi $\mathrm{C}$ et al [12] proposed methodology that focused on fingerprint based gender classification through FDA to estimate gender by analyzing fingerprints using 2D DWT and PCA on internal database of 400 persons of different age and gender they successfully obtained the classification rate of $70 \%$. 
Ravi W et al [13] proposed a method for gender Identification focused on RVA and DCT coefficients, Age and gender are classified on the basis of ridge to valley area, entropy and RMS value of DCT Coefficients of fingerprints.

PragyaBharti and Dr.C.S.Lamba et al [14] proposed a methodology using DWT based gender classification. The features were computed using DWT Using 5-level Haar Wavelet Transform; the directional images of fingerprints are obtained from an internal database of 300 images. Neural Network are used to classify and obtain accuracy rate of $91.30 \%$.

Samta G and Prabhakar et al [15] has proposed a method of fingerprint based gender classification using DWT \& artificial neural network is done. The two methods are combined for gender classification. First method is the wavelet transformation employed to extract fingerprint features by doing decomposition up to 5 levels. Second method is the back propagation of artificial neural network algorithm used for the process of male and female identification. This algorithm has experimented on database of 550 fingerprints in which 275 were male fingerprints and 275 were female fingerprints, overall classification rate of $91.45 \%$ has beenachieved.

\section{PROPOSED METHODOLOGY}

The general steps involved in gender identification from fingerprints are as shown in following figure 1

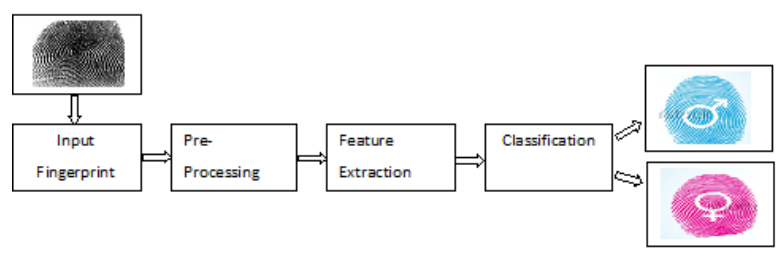

Fig 1: General approach involved in the Gender Identification System

\subsection{Image Acquisition}

As per the study there is no standard database which contains fingerprints of male and female. So we have created our own database for conducting experiment on gender classification based on fingerprints. In the database fingerprints data is collected from different age groups and these were chosen from urban and rural area. The acquisition of the fingerprint was made by "Fingkey hamster 2 nd scanner manufacture by nitgen biometric solution [30 with interface USB 2.0]". The resolution of the captured images is of 512 DPI in gray scale. The main purpose for the creation of database is to check the robustness in the gender identification. Database contains 74 persons fingerprint images each 10 fingers images totally we have 740 images of male and female fingerprint image [4][11].

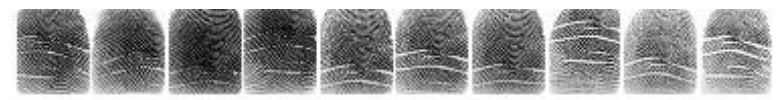

Fig 2: Sample of fingerprints

\subsection{Pre-Processing}

Before going to feature extraction initially we have to go for pre-processing, in our case we have performed background elimination, cropping, converting color image into binary image etc. which makes it suitable for further processing.[4][11]Further we have normalized the enhanced fingerprint image to size $164 \times 164$.

\subsection{Feature Extraction}

In proposed methodology Daubechies Orthogonal Wavelets (db9) used for creating feature vector as Wavelets have been shown to be useful for texture analysis shown in literature[17][19], and for computational model Standard deviation and entropy is calculated upon the fingerprint images. DWT decomposes an image into sub-bands that are localized in frequency and orientation. The 2-D wavelet decomposition of an image will results in four decomposed sub-band images referred to as low-low(LL), low-high(LH), high-low(HL), and high-high(HH).

Typically image decomposition is generally repeated on each fingerprint which undergoes eight levels of decomposition and from this co-occurrence matrix by repeating we compute thirty two features such correlation analysis (CA), correlation Variance $(\mathrm{CV})$, correlation horizontal difference $(\mathrm{CH})$ and diagonal difference (CD), entropy and standard deviation so on, then obtained feature vector is of size $8 * 4=32$ dimensions. The standard deviation of the image gives a measure of the amount average contrast and is expressed below

$$
\sigma=\sqrt{\frac{1}{N-1} \sum_{i=0}^{N}(x-\text { ? })^{2}}
$$

The entropy of the image gives a measured in expressed below

$S=-\sum P i \log _{2} P i$

Further, all fingerprints from the database undergo the decomposition and featured vector value of the image is further combined with Gabor filters.

\subsection{Gabor Filters}

Gabor is popular tool [18] in computer vision and image processing many applications, such as compression, detection, recognition, image retrieval have been investigated. In our work feature computation is carried out by combining with Gabor filters. Feature vector is created by calculating mean squared energy and mean amplitude from each scale of 5 and 6 filter orientation with a convolution done via the FFT (Fast Fourier transform)

$$
\begin{aligned}
& G(x, y: f, \theta)=\exp \left\{-1 / 2\left[\frac{x^{2}}{\delta \int_{x}^{2}}+\frac{y 2}{\delta \int_{y}^{2}}\right]\right\} \cos \left(2 \pi f x^{\prime}\right), \ldots \ldots(3) \\
& \mathrm{x}^{\prime}=\mathrm{x} \sin \theta+\mathrm{y} \cos \theta \\
& \mathrm{y}^{\prime}=\mathrm{x} \cos \theta-\mathrm{y} \sin \theta
\end{aligned}
$$

Where, $x^{\prime}$ and $y^{\prime}$ are the deviations of the Gaussian envelope along the $\mathrm{x}$ and $\mathrm{y}$ axis. The parameters $f$ and $\theta$ are respectively, the central frequency and the rotation of the Gabor filter. To obtain the Gabor-filtered image $f(\mathrm{x}, \mathrm{y})$ of a given image $\mathrm{i}(\mathrm{x}, \mathrm{y})$ the $2 \mathrm{D}$ convolution operation $(*)$ is performed. The selection of parameters $x, y, f$, and $\theta$ plays an important role in the filter's operation. Five Orientations, $\theta=$ $\theta, \frac{\pi}{4}, \frac{\pi}{2}, \pi, 3 \pi / 4$,where used and frequency $f$ was set to $2,2.5,3,3.5,4 \& 4.5$, Given the Gabor filter modulates by cosine of $f$, large values of lead to a compressed cosine and, consequently, the filter output is more likely to show fast or frequent changes in fingerprints. The obtained feature vector 
is of 92 features each from male and female fingerprint images.

\subsection{Classification}

As per the literature it is observed that generally for Gender Identification [5-21] ridge related parameters such as fingerprint ridge count, ridge density, ridge width and fingerprint patterns are promptly used. In this paper traditional ridge related analysis, has been attempted to analyze the fingerprints on structured based classification techniques such as LDA \& QDA classification.

\section{EXPERIMENTAL ANALYSIS}

In the proposed method experiment is carried out on 740 fingerprint images which were collected from different age groups of the rural and urban population 370 male and 370 female .The discrete features extraction(DWT) and Gabor based features are extracted. For analysis 370 male and 370 female fingerprints are trained and tested. The linear Discriminant analysis (LDA) and quadratic Discriminant analysis (QDA) classifiers are used to classify the gender by using below algorithm:

Step-1: Pre-processing i.e. noise removal, images resize, etc. Step-2: Normalize gray scale image to size of 164x164 and define the co-occurrence matrix.

Step-3: From the co-occurrence matrix computes 32 features by DWT.

Step-4: Further compute 32 features from each co-occurrence matrix and formed feature vector of size $32+60=92$ dimensions (Extract the 60 Gabor features from each input finger print image.)

Step-5: Apply LDA classifier and test the accuracy using 10 fold cross validation.

Step-6: Apply QDA classifier and test the accuracy using 10 fold cross validation. End of the algorithm.

In our work we used the structured based classification techniques such as (LDA) linear Discriminant analysis and quadratic Discriminant analysis (QDA) classifiers attempted for classification, we also tried to test with other classifiers i.e. by $\mathrm{K}-\mathrm{Nearest}$ Neighbor $(\mathrm{KNN})$ classifier the confusion matrix is shown in Table 1

Table 1. Confussion Matrix

\begin{tabular}{|l|l|l|l|l|l|}
\hline \multicolumn{2}{|c|}{ QDA } & \multicolumn{2}{c|}{ LDA } & \multicolumn{2}{c|}{ KNN } \\
\hline Male & Female & Male & Female & Male & Female \\
\hline 357 & 13 & 335 & 35 & 323 & 47 \\
\hline 13 & 357 & 39 & 331 & 51 & 319 \\
\hline
\end{tabular}

In Table 2 tried to show qualitative comparison between other well-known methods, classification rate using Quadratic Discriminant Analysis (QDA) Linear Discriminant Analysis (LDA) and KNN K-Nearest Neighbor is also shown below

Table 2.Classification Rate

\begin{tabular}{|c|c|}
\hline Classifiers & Overall Accuracy \\
\hline $\begin{array}{c}\text { Quadratic Discriminant } \\
\text { Analysis(QDA) }\end{array}$ & $97 \%$ \\
\hline $\begin{array}{c}\text { Linear Discriminant } \\
\text { Analysis(LDA) }\end{array}$ & $89.15 \%$ \\
\hline K-Nearest Neighbor (KNN) & $87.07 \%$ \\
\hline
\end{tabular}

\section{RESULT ANALYSIS}

In the following section the proposed methodology has been compared with other methodology from the related recent work, which has been shown in table 3

Table 2. Comparing Proposed method with Recent Work

\begin{tabular}{|c|c|c|c|}
\hline Title & $\begin{array}{l}\text { Method } \\
\text { Used }\end{array}$ & $\begin{array}{l}\text { Accuracy } \\
\text { in } \%\end{array}$ & Remarks \\
\hline $\begin{array}{l}\text { Rijo Jackson } \\
\text { Tom et al[10] }\end{array}$ & $\begin{array}{l}\text { DWT and } \\
\text { PCA }\end{array}$ & $70 \%$. & $\begin{array}{l}400 \text { images } \\
\text { internal } \\
\text { database has } \\
\text { formed. }\end{array}$ \\
\hline $\begin{array}{l}\text { Pallavi Chand } \\
\text { et.al[12] }\end{array}$ & $\begin{array}{l}\text { DWT and } \\
\text { SVD }\end{array}$ & $80 \%$. & $\begin{array}{l}\text { i) } 100 \text { images } \\
\text { dataset has been } \\
\text { made. ii) K-NN } \\
\text { Classifiers }\end{array}$ \\
\hline $\begin{array}{l}\text { S. S. Gornale } \\
\text { et al[11] }\end{array}$ & $\begin{array}{l}\text { FFT, } \\
\text { Eccentricity } \\
\text { and Major } \\
\text { Axis } \\
\text { Length. }\end{array}$ & $80 \%$ & $\begin{array}{l}1000 \text { images of } \\
\text { fingerprint used }\end{array}$ \\
\hline $\begin{array}{ll}\text { Ritu } & \text { Kaur } \\
\text { et.al[7] } & \\
\end{array}$ & $\begin{array}{l}\text { FFT, DCT } \\
\text { and PSD }\end{array}$ & $90 \%$ & $\begin{array}{l}220 \text { images } \\
\text { database used }\end{array}$ \\
\hline $\begin{array}{l}\text { Pragya Bharti } \\
\text { et.al[14] }\end{array}$ & $\begin{array}{l}\text { DWT } \\
\text { Using 5- } \\
\text { level Haar } \\
\text { Wavelet }\end{array}$ & $91.30 \%$ & $\begin{array}{l}\text { i) } 300 \\
\text { fingerprint } \\
\text { images used. } \\
\text { ii)Neural } \\
\text { Networks } \\
\end{array}$ \\
\hline $\begin{array}{l}\text { Samta Gupta } \\
\text { et.al[15] }\end{array}$ & DWT & $91.45 \%$ & $\begin{array}{l}\text { i) } 550 \\
\text { fingerprint } \\
\text { images used. } \\
\text { ii) Neural } \\
\text { network }\end{array}$ \\
\hline $\begin{array}{l}\text { Gnanasivam .P } \\
\text { et.al[6] }\end{array}$ & $\begin{array}{l}\text { DWT and } \\
\text { SVD }\end{array}$ & $91.67 \%$ & $\begin{array}{l}3570 \text { image } \\
\text { internal } \\
\text { database used }\end{array}$ \\
\hline $\begin{array}{l}\text { S. S. Gornale } \\
\text { et.al[4] }\end{array}$ & $\begin{array}{l}\text { Haralick } \\
\text { Texture } \\
\text { features }\end{array}$ & $94 \%$ & $\begin{array}{l}\text { i) } 600 \text { images of } \\
\text { fingerprints } \\
\text { used } \\
\text { ii)Quadratic } \\
\text { Discriminant } \\
\text { Analysis (QDA) }\end{array}$ \\
\hline $\begin{array}{l}\text { Gnanasivam .P } \\
\text { et.al[5] }\end{array}$ & $\begin{array}{l}\text { FFT, DCT } \\
\text { and PSD }\end{array}$ & $94.85 \%$ & $\begin{array}{l}\text { Threshold used } \\
\text { with } 400 \text { image } \\
\text { data set. }\end{array}$ \\
\hline $\begin{array}{l}\text { Proposed } \\
\text { Method }\end{array}$ & $\begin{array}{l}\text { Entropy } \\
\text { and } \\
\text { Standard } \\
\text { Mean } \\
\text { Deviation } \\
\text { DWT (Db } \\
\text { 9) \& } \\
\text { Gabor } \\
\text { Filters }\end{array}$ & $97 \%$ & $\begin{array}{l}\text { i)740 images of } \\
\text { fingerprints } \\
\text { used } \\
\text { ii) Quadratic } \\
\text { Discriminant } \\
\text { Analysis (QDA) }\end{array}$ \\
\hline
\end{tabular}

\section{CONCLUSION}

From the literature it is observed that a good number of researchers have worked on gender classification using different approaches and forecasted some promising results with their own datasets. But still there is a scope for developing a robust algorithm using different parameter, in 
proposed work an attempt is made combined features using DWT and Gabor for 370 male samples and 370 female samples of good quality. It is found that the proposed algorithm produces accurate decision of $97 \%$. In future, the work will be extended to build robust algorithm with more generalize properties different features it can be applied in gender classification which will be more accurate and suitable for all types of machine learning approaches.

\section{REFERENCES}

[1] Biometrics History ,"National Science and Technology council (NSTC) of United State", March 2006

[2] Anil K. Jain, Karthik Nandakumar, Xiaoguang Lu, and Unsang park, "Integrating Faces, Fingerprints, and Soft Biometric Traits for user Recognition." Proceedings of Biometric Authentication Workshop, LNCS 3087, PP.259-269, PRAGUE,-MAY 2004.

[3] Sudesh Gundadinet.al., "Sex Determination from Fingerprint Ridge Density", International Journal of Medical Update 2007 Jul-Dec;2(2):4-7.

[4] S. S. Gornale, Mallikarjun Hangarge, Rajmohan Pardeshi ,Kruthi R" Haralick Feature Descriptors for Gender Classification Using Fingerprints: A Machine Learning Approach “,IJARCSSE Volume 5,Issue 9,September 15.

[5] Gnanasivam .P, and Dr. Muttan S, "Gender Identification Using Fingerprint through Frequency Domain analysis", European Journal of Scientific Research ISSN 1450216X Vol.59 No.2-2011.

[6] Gnanasivam .P, and Dr. Muttan S, "Fingerprint Gender Classification Using Wavelet Transform and Singular Value Decomposition", International Journal of Computer Science Issues, Vol. 9, Issue 2, No 3, March 2012.

[7] Ritu Kaur and Susmita Ghosh Mazumdar, "Fingerprint Based Gender Identification using Frequency Domain Analysis", International Journal of Advances in Engineering \& Technology, March 2012.@IJAET ISSN: 2231-1963.

[8] RituKaur and Susmita Ghosh Mazumdar, Mr. Devanand Bhonsle, "A Study On Various Methods of Gender Identification Based on Fingerprints", International Journal of Emerging Technology and Advanced Engineering, ISSN 2250-2459, Volume 2,Issue 4, April 2012Electron., submitted for publication.

[9] Naveen Kumar Jain, Sunil Sharma, Anurag Paliwal., A Real Time Approach To Determine The Gender Using Fingerprints", IJAIR ISSN: 2278-7844, PP:229-233, 2012.

[10] Rijo Jackson Tom, T. Arulkumaran, "Fingerprint Based Gender Classification Using 2D Discrete Wavelet Transforms and Principal Component Analysis", International Journal of Engineering Trends and Technology, Volume 4 Issue 2,2013 M. Young, The
Technical Writers Handbook. Mill Valley, CA: University Science, 1989.

[11] S. S. Gornale, Geetha D, Kruthi R "Analysis of fingerprint image for gender classification using spatial and frequency domain analysis", American International Journal of Research in Science, Technology, Engineering and Mathematics", ISSN (Print): 2328-3491, ISSN (Online): 2328-3580, ISSN (CD-ROM): 2328-3629, PP: 46-50, 2013

[12] Pallavi Chand, Shubhendu Kumar Sarangi, "A Novel Method for Gender Classification Using DWT and SVD Techniques", International Journal of Computer Technology \& Applications, Vol 4 (3),445-449, MayJune 2013 Available online@www.ijcta.com.

[13] Ravi Wadhwa, ManinderKaur, Dr. K.V.P. Singh, “Age and Gender Determination from Finger Prints using RVA and DCT Coefficients", IOSR Journal of Engineering (IOSRJEN) e-ISSN: 2250-3021, p-ISSN: 2278-8719 Vol. 3, Issue 8 (August. 2013), PP: 05-09

[14] Pragya Bharti and Dr. C. S. Lamba "DWT-Neural Network based Gender Classification", International Journal of Digital Application \& Contemporary Research, ISSN: 2319-4863 Volume 2, Issue 8, March 2014.

[15] Samta Gupta, A. Prabhakar Rao, "Fingerprint Based Gender Classification Using Discrete Wavelet Transform \& Artificial Neural Network", International Journal of Computer Science and Mobile Computing, ISSN 2320 088X Vol. 3, Issue. 4, April 2014, pg.1289 - 1296.

[16] Mr. Jageshvar K. Keche, Mr. Vikas K. Yeotikar, Dr. Mahendra P. Dhore " Human Face Recognition using Wavelet Transform based Approach "International Journal of Computer \& Mathematical Sciences IJCMS ISSN 2347 - 8527 Volume 3, Issue 9 November 2014.

[17] Muhammad Umer Munir and Dr. Muhammad Younas Javed," Fingerprint Matching using Gabor Filters" National Conference on Emerging Technologies 2004.

[18] MikelGalar A, Joaquín Derrac g, Daniel Peralta b, Isaac Trigueroe,f,b, Daniel Paternaina, Carlos Lopez-Molina a," A survey of fingerprint classification Part I: Taxonomies on feature extraction methods and learning models", Knowledge-Based Systems 81 (2015) 76-97.

[19] Shahid Akbar , Ashfaq Ahmad, Maqsood Hayat, "Identification of Fingerprint Using Discrete Wavelet Transform in Conjunction with Support Vector Machine", IJCSI International Journal of Computer Science Issues, Vol. 11, Issue d5, No 1, September 2014 ISSN (Print): 1694-0814 | ISSN (Online): 1694-0784.

[20] Sharath Pankanti, Alan Jea, NaliniRatha and Ruud Bolle "Fingerprint Representation Using Localized Texture Features" The 18th International Conference on Pattern Recognition (ICPR'06). 